\title{
Oxidation of Quercetin by Myeloperoxidase
}

\author{
Tatjana Momić, Jasmina Savić, and Vesna Vasić \\ Laboratory of Physical Chemistry, Vinča Institute of Nuclear Sciences, P.O. Box 522, 11001 Belgrade, Serbia
}

Correspondence should be addressed to Tatjana Momić, momict@vinca.rs

Received 3 February 2009; Accepted 12 March 2009

Recommended by Benjaram M. Reddy

Study of effect of myeloperoxidase on quercetin at $\mathrm{pH}$ 6.0 indicated quercetin oxidation via the formation of the oxidation product. The stability of quercetin and oxidation product was investigated as a function of time by using spectrophotometric and HPLC techniques. The apparent pseudo first-order rate constants were calculated and discussed.

Copyright (C) 2009 Tatjana Momić et al. This is an open access article distributed under the Creative Commons Attribution License, which permits unrestricted use, distribution, and reproduction in any medium, provided the original work is properly cited.

\section{Introduction}

Flavonol quercetin (Q) (3,5,7,3', $4^{\prime}$-pentahydroxyflavone) (Scheme 1) due to its phenolic structure is a strong antioxidant and free radical scavenger [1]. Oxidation of quercetin during its antioxidative functions is usually accompanied by the production of the quercetin radical anion, superoxide, and hydrogen peroxide [2]. Quercetin undergoes autoxidation - the nonenzymatic reaction with atmospheric oxygen. Also, it is known that one-electron oxidation of quercetin is catalyzed by different peroxidases like lactoperoxidase (LPO) [3] and horseradish peroxidase (HRP) [4-7] in the presence of $\mathrm{H}_{2} \mathrm{O}_{2}$.

The heme enzyme myeloperoxidase (MPO) is oxidant enzyme in the process of inflammation and atherogenesis [8]. Myeloperoxidase is relatively nonspecific with respect to its reducing substrates. This enzyme is able to oxidize different substrates among which anilines and phenols [9-11]. This letter deals with quercetin oxidation by myeloperoxidase- $\mathrm{H}_{2} \mathrm{O}_{2}$ system.

\section{Experimental}

2.1. Chemicals. Quercetin dihydrate (Sigma-Aldrich) of the highest quality available (98\%) was used without purification. $1 \times 10^{-3} \mathrm{M}$ stock solution of quercetin was prepared in methanol immediately before the experiments. For all experiments, freshly prepared solutions of quercetin were made by dilution of the appropriate amount of the stock solution with phosphate buffer at $\mathrm{pH}$ 6.0. Myeloperoxidase was purified from human neutrophils to a purity index
$\left(\mathrm{A}_{430} / \mathrm{A}_{280}\right)$ greater than 0.70 as described previously [12]. Its concentration was calculated using $\varepsilon_{430}=91000 \mathrm{M}^{-1} \mathrm{~cm}^{-1}$ per heme [13]. Hydrogen peroxide solutions were prepared daily by diluting a stock solution, and the concentration was determined using $\varepsilon_{240}=43.6 \mathrm{M}^{-1} \mathrm{~cm}^{-1}$ [14]. Redistilled water was used in all experiments.

2.2. Oxidation of Quercetin by Myeloperoxidase. Quercetin $\left(5 \times 10^{-5} \mathrm{M}\right)$ was incubated in $50 \mathrm{mM}$ phosphate buffer, $\mathrm{pH}$ 6.0, with various concentrations of MPO. Reaction was started by the addition of $50 \mu \mathrm{M} \mathrm{H}_{2} \mathrm{O}_{2}$, and UV absorbance changes were recorded. For the HPLC analysis, reaction was stopped after 30 minutes by adding catalase $(100 \mu \mathrm{g} / \mathrm{mL})$. The reaction mixture was centrifuged for 2 minutes at $10000 \mathrm{rpm}$. The clear supernatant was analyzed by HPLC.

2.3. HPLC Analysis. HPLC equipment consisted of an HP 1100 Series chromatograph coupled with a DAD. Chromatographic separations were run on a C18 Pinnacle ODS column (Restek, $250 \mathrm{~mm} \times 4.6 \mathrm{~mm}, 5 \mu \mathrm{m}$ ) using an $80: 20$ mixture of $2 \mathrm{vol} \% \mathrm{H}_{3} \mathrm{PO}_{4}$ (A) and acetonitrile (J.T. Baker) (B) as the eluent for the first 2 minutes. The linear gradient was applied from $20 \%$ to $45 \%$ B from 2 to 7 minutes. An isocratic $55: 45$ mixture was applied between 7 and 13 minutes. The eluent flow rate was $1.0 \mathrm{~mL} \mathrm{~min}^{-1}$, and the injection volume was $10 \mu \mathrm{L}$. The elutions were monitored with DAD at different wavelengths between 200 and $450 \mathrm{~nm}$.

2.4. UV-Vis Spectroscopic Studies. UV spectra were recorded on a Perkin Elmer Lambda 35 UV-Vis spectrophotometer 


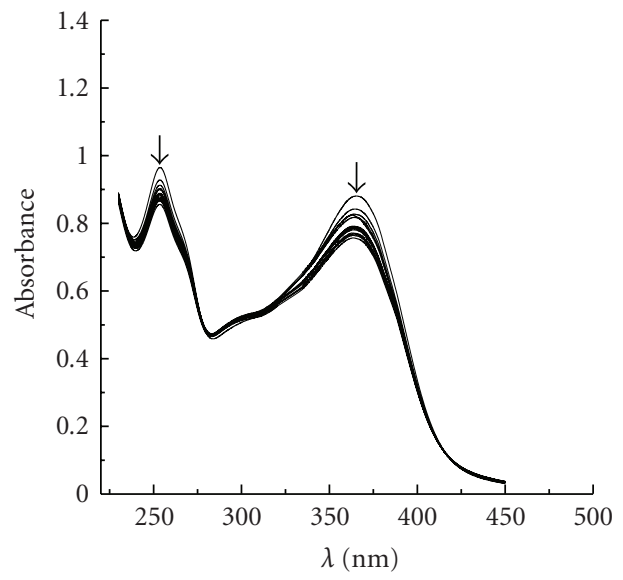

(a)

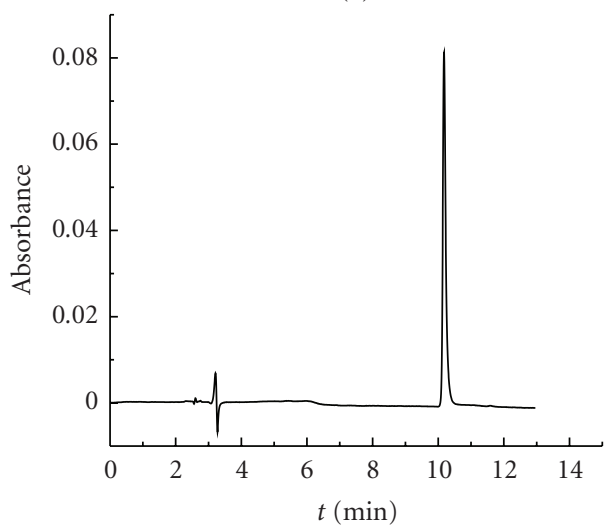

(b)

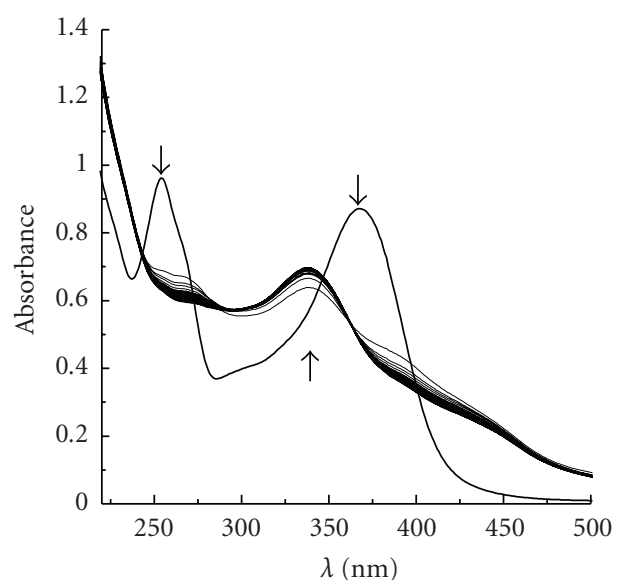

(c)

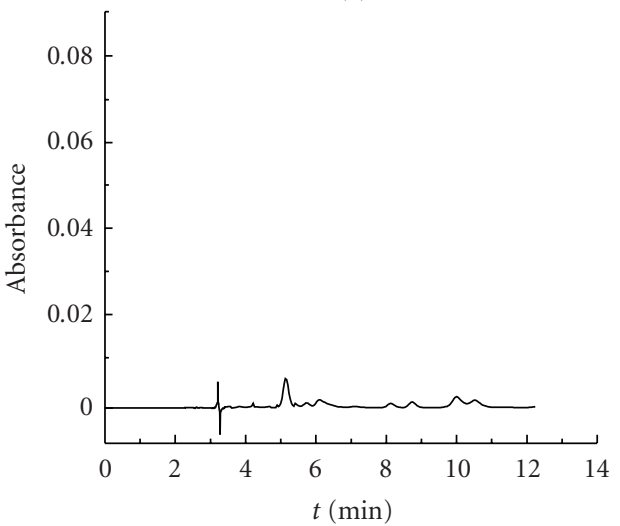

(d)

FIGURE 1: Absorption spectra and HPLC chromatograms of $5 \times 10^{-5} \mathrm{M}$ quercetin at $\mathrm{pH} 6.0$ in absence (a), (b) and presence (c), (d) of $20 \mathrm{nM}$ MPO. $50 \mu \mathrm{M} \mathrm{H}_{2} \mathrm{O}_{2}$ was present in all reaction solutions. Spectra were recorded over a period of 30 minutes; arrows indicate the direction of the change. Chromatograms were recorded after 30 minutes (b) at $\lambda_{367}$ and (d) at $\lambda_{336}$.

TABLE 1: Rate constants of quercetin oxidation.

\begin{tabular}{lcccr}
\hline & & & $k\left(\mathrm{~min}^{-1}\right) \times 10^{3}$ & \\
$\mathrm{pH}$ & Sample & Quercetin degradation & Water adduct formation & Water adduct degradation \\
\hline \multirow{2}{*}{6.0} & $\mathrm{Q}$ & $3.61 \pm 0.18$ & - & - \\
& $\mathrm{Q}+\mathrm{MPO}(20 \mathrm{nM})$ & $346.00 \pm 21.15$ & $524.60 \pm 32.30$ & $2.67 \pm 0.09$ \\
$10.0^{*}$ & Non-irradiated Q & $8.73 \pm 0.34$ & $25.12 \pm 0.93$ & - \\
& Irradiated Q & $110.00 \pm 35.25$ & $96.91 \pm 0.12$ & $10.13 \pm 0.56$ \\
\hline
\end{tabular}

*Reference [17].

equipped with thermostatted quartz cell. The temperature in the cell was kept at $25 \pm 0.05^{\circ} \mathrm{C}$ with a water-thermostatted bath.

\section{Results and Discussion}

We investigated the effect of MPO on $5 \times 10^{-5} \mathrm{M}$ quercetin in phosphate buffer, pH 6.0 in the presence of $50 \mu \mathrm{M} \mathrm{H}_{2} \mathrm{O}_{2}$ at $25^{\circ} \mathrm{C}$, spectrophotometrically and by HPLC. The following concentrations of enzyme were used: $5,11,15,20,50,100$, 150 , and $200 \mathrm{nM}$.
At the absorption spectra of samples in which concentration of MPO was $\leq 11 \mathrm{nM}$, two quercetin absorption bands (254 $\mathrm{nm}$ and $367 \mathrm{~nm}$ ) were observed (Figure 1(a)). The same results were yielded when $\mathrm{MPO}$ or $\mathrm{H}_{2} \mathrm{O}_{2}$ was omited from the mixture.

The absorption spectra of samples in which concentration of MPO was $\geq 15 \mathrm{nM}$ showed the decay of quercetin absorption bands at $254 \mathrm{~nm}$ and $367 \mathrm{~nm}$. At the same time simultaneous rise of the absorption band at 336$342 \mathrm{~nm}$, depended on MPO concentration, was observed (Figure 1(c)), typical of oxidation product formation [16]. 
<smiles>O=c1c(O)c(-c2ccc(O)c(O)c2)oc2cc(O)cc(O)c12</smiles><smiles>CCO[Mg]O[Na]</smiles><smiles>[R20]C1(O)C(=O)c2c(O)cc(O)cc2OC1([R20])c1ccc(O)c(O)c1</smiles>

Scheme 1: Oxidation of quercetin by MPO/ $\mathrm{H}_{2} \mathrm{O}_{2}$ system (modified from [15]).

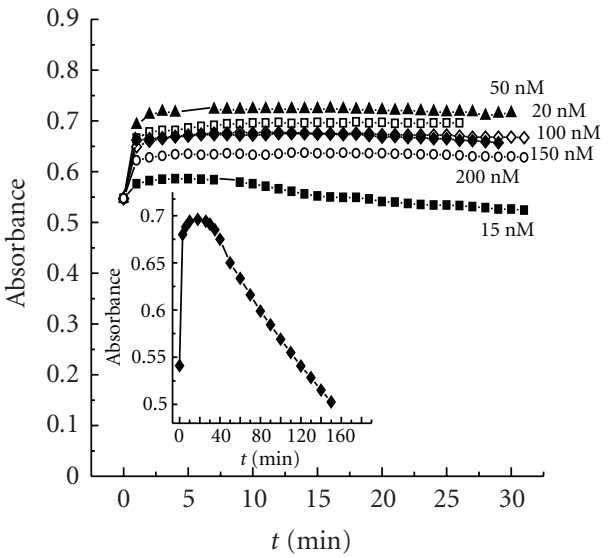

(a)

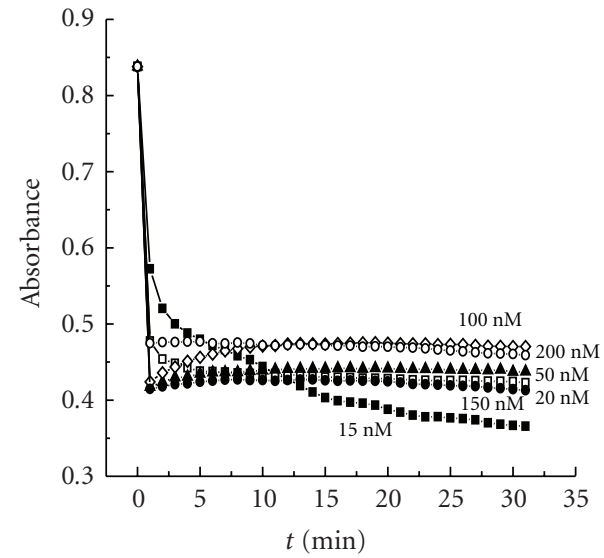

(b)

FIGURE 2: Change of absorbance of quercetin in the presence of various MPO concentrations in the function of time, at pH 6.0 (a) formation of quercetin oxidation product at $\lambda_{336}$; Inset: $20 \mathrm{nM}$ MPO and (b) degradation of quercetin oxidation product at $\lambda_{367}$.

Moreover, two well-defined isosbestic points at 290 and $364 \mathrm{~nm}$ indicate that there was no significant accumulation of intermediates in the reaction of oxidation product formation (Figure 1(c)). These spectral changes are analogous to those occurring upon autoxidation of quercetin in water [16] and UV irradiation [17] as well as oxidation with some oxidants in organic solvents [16].

The HPLC analysis of quercetin solution treated with MPO for 30 minutes (Figure $1(\mathrm{~d})$ ) revealed that concentration of quercetin (retention time 10 minutes) was negligible.
Also, formation of major oxidation product (retention time 5.26 minutes) which was more polar than quercetin was detected (Figure 1(d)). From literature data and the obtained spectrophotometric and HPLC results in this work, we assume that the oxidation product detectable at $336-342 \mathrm{~nm}$ results from $\mathrm{H}_{2} \mathrm{O}$ addition on the $p$-quinonemethide formed by $\mathrm{H}$-atom abstraction at $3-\mathrm{OH}$ and $4^{\prime}-\mathrm{OH}$ of quercetin and subsequent rearrangement of the central ring [16]. The complete sequence of quercetin autoxidation induced by oxidants and catalyzed by metal ions is described earlier $[15,16]$ (Scheme 1). 
According to spectrophotometric and HPLC experimental data, quercetin degradation (1) and oxidation product formation (2) as the function of time followed the relation

$$
\begin{aligned}
A_{\mathrm{Q}, t} & =A_{0} e^{-k t}, \\
A_{\text {oxid }, t} & =A_{\infty}\left(1-e^{-k t}\right),
\end{aligned}
$$

where $A_{\mathrm{Q}, t}$ and $A_{\text {oxid, } t}$ are the absorbances proportional to the quercetin and its oxidation product concentrations, respectively, after an irradiation period of time $t$ and $k$ is the overall pseudo first-order rate constant. $A_{0}$ and $A_{\infty}$ are the absorbance proportional to the initial concentration of quercetin and the concentration of the oxidation product on the plateau of the kinetics curve, respectively.

The kinetic curves that describe the quercetin degradation and the formation of the oxidation product in the presence of different MPO, concentrations are shown in Figure 2. In the presence of MPO concentration that was $\geq 15 \mathrm{nM}$ oxidation product was formed at the first minute of reaction (Figure 2(a)). The overall apparent first-order rate constants for the oxidation product formation and quercetin transformation to its degradation products were determined from the kinetic curves and are presented in Table 1. For comparison, in Table 1 we also presented values for these constants obtained for quercetin oxidation by UV irradiation [17].

The rate of quercetin oxidation by MPO at $\mathrm{pH} 6.0$ is 3fold faster compared with the rate of quercetin oxidation by UV irradiation at $\mathrm{pH}$ 10.0. Moreover, product obtained for quercetin oxidation by MPO at $\mathrm{pH} 6.0$ is more stable than product of quercetin oxidation by UV irradiation at $\mathrm{pH} 10.0$.

\section{Acknowledgment}

We wish to express our gratitude to the Ministry of Science and Technological Development of the Republic of Serbia supported this work through Project 142051.

\section{References}

[1] L. Magnani, E. M. Gaydou, and J. C. Hubaud, "Spectrophotometric measurement of antioxidant properties of flavones and flavonols against superoxide anion," Analytica Chimica Acta, vol. 411, no. 1-2, pp. 209-216, 2000.

[2] N. Cotelle, J.-L. Bernier, J.-P. Catteau, J. Pommery, J.-C. Wallet, and E. M. Gaydou, "Antioxidant properties of hydroxyflavones," Free Radical Biology and Medicine, vol. 20, no. 1, pp. 35-43, 1996.

[3] D. Metodiewa, A. K. Jaiswal, N. Cenas, E. Dickancaité, and J. Segura-Aguilar, "Quercetin may act as a cytotoxic prooxidant after its metabolic activation to semiquinone and quinoidal product," Free Radical Biology and Medicine, vol. 26, no. 1-2, pp. 107-116, 1999.

[4] H. Yamasaki, Y. Sakihama, and N. Ikehara, "Flavonoidperoxidase reaction as a detoxification mechanism of plant cells against $\mathrm{H}_{2} \mathrm{O}_{2}$," Plant Physiology, vol. 115, no. 4, pp. 14051412, 1997.

[5] G. Galati, T. Chan, B. Wu, and P. J. O’Brien, "Glutathionedependent generation of reactive oxygen species by the peroxidase-catalyzed redox cycling of flavonoids," Chemical Research in Toxicology, vol. 12, no. 6, pp. 521-525, 1999.
[6] D. P. Makris and J. T. Rossiter, "An investigation on structural aspects influencing product formation in enzymic and chemical oxidation of quercetin and related flavonols," Food Chemistry, vol. 77, no. 2, pp. 177-185, 2002.

[7] U. Takahama, "Spectrophotometric study on the oxidation of rutin by horseradish peroxidase and characteristics of the oxidized products," Biochimica et Biophysica Acta, vol. 882, no. 3, pp. 445-451, 1986.

[8] S. J. Klebanoff, "Myeloperoxidase," Proceedings of the Association of American Physicians, vol. 111, no. 5, pp. 383-389, 1999.

[9] J. K. Hurst, "Myeloperoxidase: active site structure and catalytic mechanism," in Peroxidases in Chemistry and Biology, J. Everse, K. E. Everse, and M. B. Grisham, Eds., pp. 37-62, CRC Press, Boca Raton, Fla, USA, 1991.

[10] E. Shacter, R. L. Lopez, and S. Pati, "Inhibition of the myeloperoxidase- $\mathrm{H}_{2} \mathrm{O}_{2}$-Cl-system of neutrophils by indometacin and other non-steroidal anti-inflammatory drugs," Biochemical Pharmacology, vol. 41, no. 6-7, pp. 975-984, 1991.

[11] A. J. Kettle, C. A. Gedye, M. B. Hampton, and C. C. Winterbourn, "Inhibition of myeloperoxidase by benzoic acid hydrazides," Biochemical Journal, vol. 308, no. 2, pp. 559-563, 1995.

[12] R. L. Olsen and C. Little, "Purification and some properties of myeloperoxidase and eosinophil peroxidase from human blood," Biochemical Journal, vol. 209, no. 3, pp. 781-787, 1983.

[13] T. Odajima and I. Yamazaki, "Myeloperoxidase of the leukocyte of normal blood-I: reaction of myeloperoxidase with hydrogen peroxide," Biochimica et Biophysica Acta, vol. 206, no. 1, pp. 71-77, 1970.

[14] R. J. Beers Jr. and I. W. Sizer, "A spectrophotometric method for measuring the breakdown of hydrogen peroxide by catalase," Journal of Biological Chemistry, vol. 195, no. 1, pp. 133-140, 1952.

[15] O. Dangles, C. Dufour, and S. Bret, "Flavonol-serum albumin complexation. Two-electron oxidation of flavonols and their complexes with serum albumin," Journal of the Chemical Society Perkin Transactions, vol. 2, no. 4, pp. 737-744, 1999.

[16] H. E. Hajji, E. Nkhili, V. Tomao, and O. Dangles, "Interactions of quercetin with iron and copper ions: complexation and autoxidation," Free Radical Research, vol. 40, no. 3, pp. 303320, 2006.

[17] T. Momić, J. Savić, U. Černigoj, P. Trebše, and V. Vasić, "Protolytic equilibria and photodegradation of quercetin in aqueous solution," Collection of Czechoslovak Chemical Communications, vol. 72, no. 11, pp. 1447-1460, 2007. 


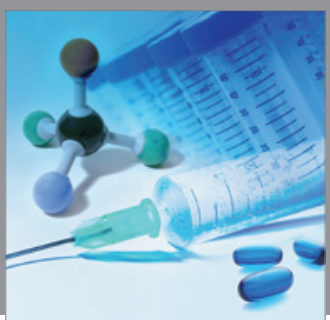

International Journal of

Medicinal Chemistry

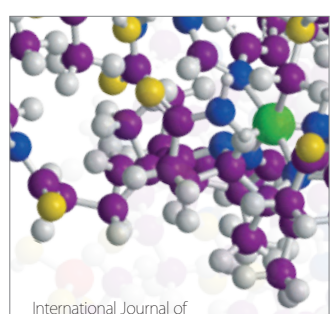

Carbohydrate Chemistry

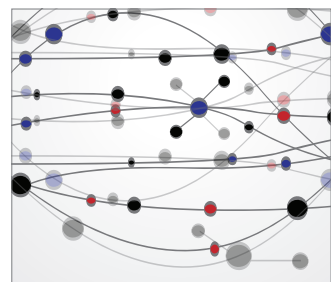

The Scientific World Journal
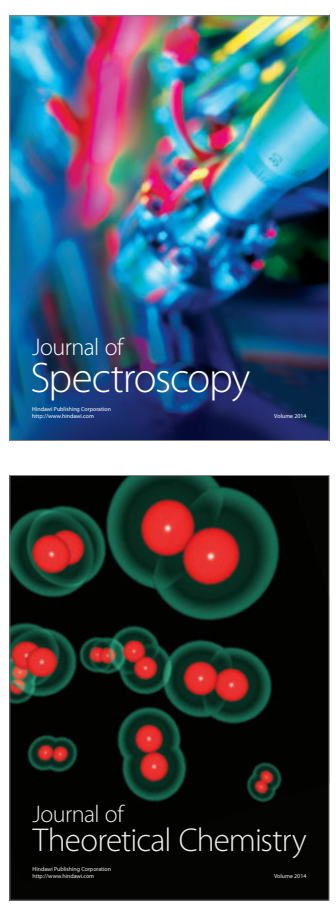
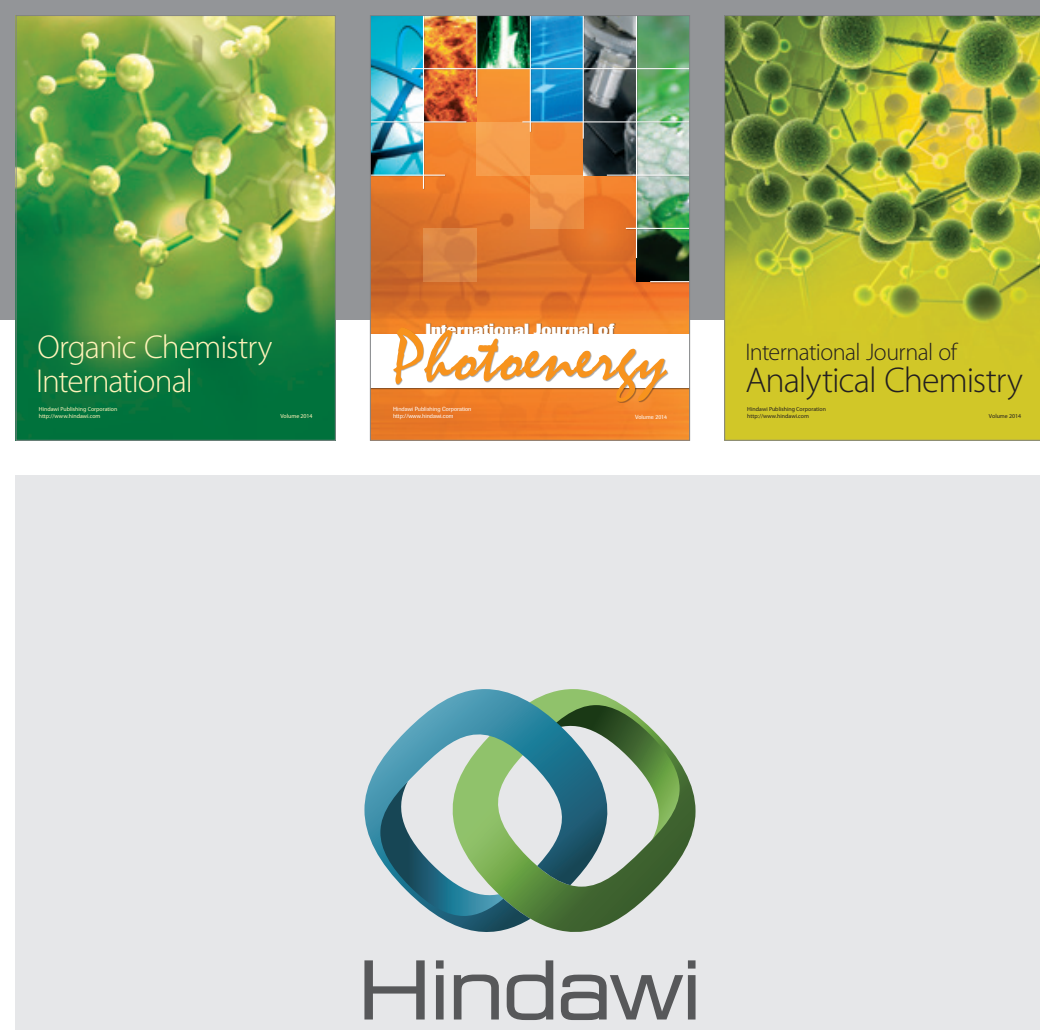

Submit your manuscripts at

http://www.hindawi.com
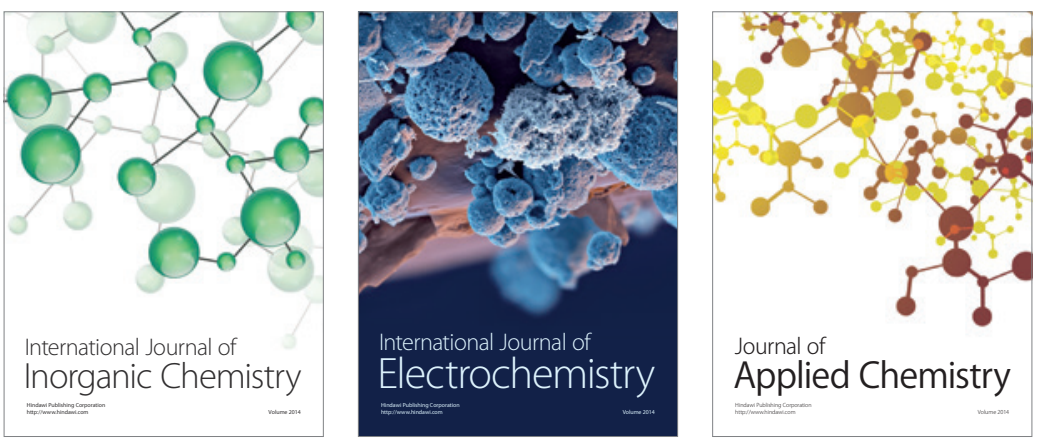

Journal of

Applied Chemistry
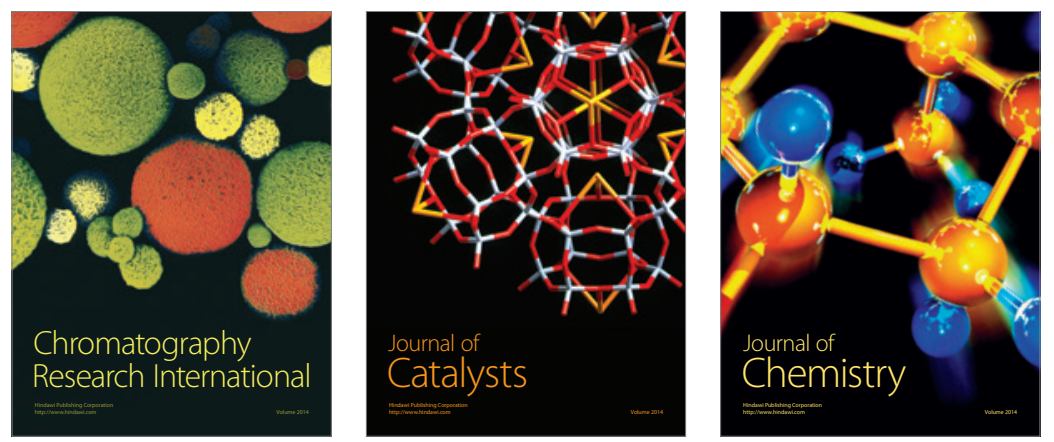
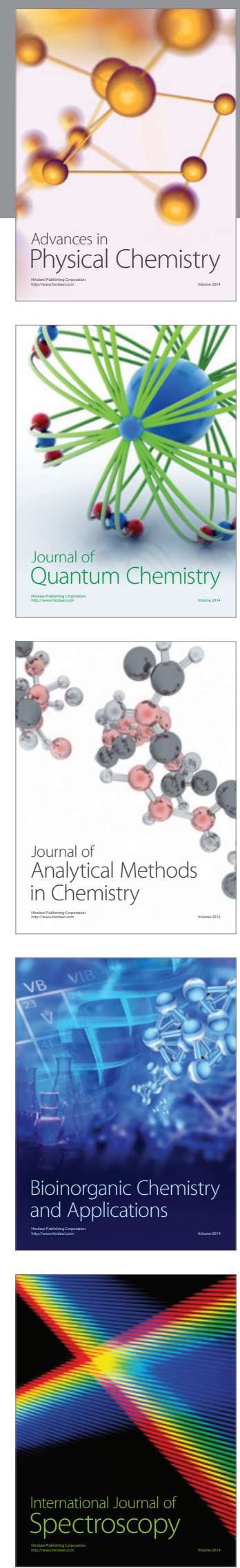